\title{
THE CONTRIBUTION OF TELEVISION IN MEDIA-AIDED LANGUAGE PROGRAMS
}

\author{
by Martha Formanek, Gerhard Clausing and Cecil Wood
}

\section{Introduction}

The medium of television has frequently been utilized as an aid or as the sole vehicle for beginning language instruction ${ }^{1}$, but its integration into a fully developed course ancl the development of dynamic interaction with the other components have often been neglected. At the University of Minnesota a unique television component has been under development and fully functional since 1965 as one part of an integrated system for language instruction. These Media-Aided Language Programs for first-year courses on the college level, first developed for German, are now also being developed for Dutch, Swedish and other languages and are designed to teach all four skills, with special emphasis on speaking.

This paper covers the following points, with specific reference to the German sequence:

1. Purpose and implementation of the television component at the University of Minnesota.

2. The development of the previous versions of our program, leading to the current version, and our experience in using them.

3. A description of the structure and format of the current television sequence and its various parts.

\footnotetext{
'For descriptions of television courses in beginning German, see the following: Joseph E. Bourgeois, "German on Television in Cincinnati," German Quarterly 32 (1959), 43-48; Albert F. Buffington, "Teaching Beginning German by Closed-Circuit Television," German Quarterly 33 (1960). 147-152; Albert F. Buffington, "A Reply to Mr. Rovener's "Appraisal of Teaching Beginning German by Closed-Circuit Television," German Quarter. ly 34 (1961), 164-173; Siegfred H. Muller, "Report on the Proceedings of the Television Committee, AATG," German Quarterly 28 (1955), 89-95; Alfred R. Neumann, "German on Television in Houston: An Informal Report," German Quarterly 29 (1956), 261-267; Helmut Plant and Christian Stehr, "Guten Tag at Oregon: An Audio-Visual Experiment," Die Unterrichtspraxis 6 (1973), No. 1, 40-50; Herbert Heichert, "Conventional Textbooks in One Foreign-Language Telecourse," German Quarterly (1959), 34-42; Philip Rovner, "An Appraisal of "Teaching Beginning German by Closed-Circuit Television," "German Quarterly 34 (1961), 154-163; Leroy R. Shaw, "German on Television at the University of Texas," German Quarterly 34 (1961), 146-153.
} 


\section{Contribution of Television}

4. The production techniques used for the various parts of the program.

5. The utilization of television and its interaction with other components.

Television is considered only a part of our instructional framework in which the student has two teachers, the television instructor and the classroom instructor. The television instructor is responsible for a controlled presentation of grammar, vocabulary and cultural information in conjunction with the textbook and the computer. Drilling is carried out through the television medium as well as through the computer, whose role as a tutor in this interactional process is explained in another publication. ${ }^{2}$ The television teacher explains grammatical structures and performs drills with the television class or with students in individualized instruction where the students play the tapes separately at times convenient for them. Since the grammatical explanations are given only in television presentations, the television teacher, in conjunction with the textbook, becomes the major source of exposure to grammatical concepts.

The classroom instructor, assisted by television and other components (computer, tapes, etc.), provides the irreplaceable element. In the classroom, interaction in the language takes place, and both instructors and students agree, in detailed questionnaires, that this is indeed the most essential part of the entire program. What the student has absorbed through the media and through his own study is applied in group work. Thus the main role of the classroom instructor is to stimulate the students to apply grammatical points, the vocabulary, and the cultural information in various ways and to expand on this information in order to reinforce what has been learned. 3

According to Bergmann, 4 there are four ways of using television in instructional programs: as an enrichment component, as a supplementary learning aid, as an integral and obligatory part of the program, and as the major instructional resource. The television compo-

\footnotetext{
${ }^{2}$ Gerhard Clausing and Cecil Wood, "The Computer-Tutor in Media Aided Language Programs"

3Audrone B. Willeke, Gerhard Clausing, Martha Formanek, and Cecil Wood, "Small Group Activities and the Role of the Individual in Media-Aided Language Programs"

4Cf. Erhard Bergmann, Schulfernsehen. Zur Entwicklung, Didaktik and Fraxis, (Frankfurt/Main: Diesterweg, 1969), p. 31 ff. Also cf. Richard C. Burke, ed., Instructional Television. Bold New Venture, (Bloomington: Indiana University Press, 1971), p. 33 ff.
} 
nent at the University of Minnesota is used both as an integral part of and an enrichment component of the instructional design. While open circuit programs were tried in the pasts, the current sequence is used for closed-circuit telecasts and individual cassette replays. All programs have been produced with the resources of the university, and can be made available to other institutions.

\section{Genesis and History}

The present television program was planned in 1964 and first produced in 1965, based on materials developed by Cecil Wood and others beginning in 1962. These materials existed in textbook form for many years 6 , and are dealt with an another publication 7 . The intention was to produce a series of 45-minute television lessons which contained grammatical explanations to accompany the textbook. At first these programs consisted only of grammar explanations which were telecast to all students of a multi-section beginning German course. They were presented in one large television classroom twice a week, both mornings and afternoons to accommodate varying schedules of the students. In the mornings, the presentation was done live and was taped simultaneously; thus it could be replayed in the afternoon as a time-saving and cost-saving device. In addition, students met with their classroom instructors three times a week in small groups of 20-25. The intent of these presentation was:

'1. To present uniform one-source grammar explanations based on tagmemics and transformation which had been used and experimentally verified simultaneously for several years.

2. To standardize the pace in all sections of this multi-section course by coordinating assignments through television.

3. To allow the possibility of replaying programs at later times.

4. To free the classroom instructor from the drudgery of grammatical explanations and drilling.

The early television programs had very little resemblance to the present version; the years between the first version and the current

'Helga Slessarev, German for Beginners I (Telecourse), (Minneapolis: University of Minnesota, 1960).

${ }^{6}$ Cecil Wood, Charlotte von Wymetal, and Wolfgang Taraba, Structural German, (Minneapolis: Gilbert Publishing Co., 1965). Revised edition by the same authors entitled Programmed German, (Minneapolis: University of Minnesota, 1971). A totally revised and expanded program, Deutsch. A Media-Aided Language Program, is planned.

7Martin Kuelbs, "The Genesis and Development of Programmed German," Research Report of the Consulting Group on Instructional Design, Univeristy of Minnesota, (1973). 


\section{Contribution of Television}

series were spent searching for the appropriate format: simple, plain, but effective ways of transmitting grammar, ways of stimulating the student, and approaches which would expose the student to increasingly complex word, phrase and textual structures of spoken German. The years of experimentation with these first-year television programs showed that television can be the major source of grammatical explanatiors, and can provide a sufficient amount of drilling, thus eliminating the reed for drilling in small group meetings.

Throughout these years careful observing of student reactions to the television lesson took place, and student feed-back continually helped in shaping the direction which the content and format of these programs took. For instance, in the first years it was observed that in the middle of the second quarter the students were obviously reluctant to attend telecasts. Only a small part of each class continued to follow grammatical explanation on the screen attentively, while the majority merely sat through these sessions engaged in other activities which were unrelated to the German course. Through these observations we realized that television lessons consisting of grammar explanations exclusively will not hold the students' interest for three quarters. It was the students' consensus at the time that the monotony of the program stood in the way of their appreciation of the medium as a learning device.

Therefore, experiments were conducted to add variety and interesting materials to the lessons. New instructors were brought in for drilling. This was unsuccessful because the students had become conditioned to responding to one man, their television teacher, only. In addition, "listening passages" were introduced, such as stories or fairy tales ("Rotkappchen"), which were told or read to students in the television presentations. Sentences from the stories were drilled, visual aids were added, wora's were flashed on the screen, and the narrated text was also displayed on the screen in order to allow an association of visuals with aural perception. Questions on the story were presented orally in order to elicit response from the students. Again it was found that since these presentations were conducted by only one person, they did not add enough variety and were therefore not particularly successful.

Among our attempts to add new elements, to provide different types of learning experiences, was the inclusion of short talks, presentations by native speakers, on topics which were thought to be of interest to students. However, it was found that in five-to-ten minute discussions or lectures, scholars, even if they were experienced teachers who were aware of the extent of the students' knowledge of the language, were unable to compress the subject matter and to 
confine themselves to the limited vocabulary and grammar of first-year German. An attempt was made to improve this method by flashing vocabulary items on the television screen as well as utilizing other visual aids, but neither of these techniques proved successful. Although oral comprehension ability was affected positively, the students were unable to converse about the topics presented in the lectures, no matter how simplified the presentations had been. This seems to indicate that such lectures really do not belong in a first-year television. course.

In order to break the monotony of the programs and make them more effective, the experiences mentioned led us to a further step. We changed the structure of the television lectures by presenting program segments that took better advantage of television; the new segments transmitted material and replicated processes that cannot be presented or simulated in the classroom. In trying to find a format in which . vocabulary and syntax as well as situational context were carefully structured and controlled, skits were developed. From the first day in 1970, these skits have been met with an overwhelmingly positive response from the students. They are not only considered entertaining, but also teach the students a great deal about the new language and culture as well as about cultural differences. The skits are from thirty seconds to three minutes in length and contain contextural variations using the grammatical structures used in the concurrent lesson, with a controlled amount of vocabulary as well as indiomatic expressions required by the situation depicted. The presentations are based on everyday situations and contain punch lines to which the student can relate and which motivate the students to discuss the topics with their classroom instructor and their fellow students. Since the students do not have scripts, but only vocabulary lists, while viewing and listening to these skits, they are motivated to listen very attentively. Furthermore, quizzes concerning the skits are administered periodically in the television classroom. These skits and quizzes, together with the grammar and drill program mentioned above, have constituted the entire television instruction since 1970.

\section{Description of the Current Version}

A. Parts of the current version

As of fall, 1973, the television instructional sequence had expanded to include the following components:

- 1. Grammar programs which contain grammatical explanations for the entire basic grammar of German and are telecast for two quarters. Drills are included as a part of the instruction.

2. Pronunciation practice tapes. These are used during the first six weeks of the first quarter only and provide explanations as well as 


\section{Contribution of Television}

examples for practicing the pronunciation of German vowels and consonants, stressing particularly those that are difficult to produce for speakers of English.

3..The "reading" video tape, used in the sixth week of the first quarter of instruction. It teaches the student to read more efficiently by moving him toward an understanding of the structure of the German sentence without resorting to word-for-word translation, a method involving "contextual comprehension." This tape is introduced at the time intensive reading begins; it is used only once.

4. Skits ("Es wird Deutsch gesprochen") These program segments are telecast beginning with the sixth week of the first quarter and continue throughout the second and third quarters. In the third quarter, they constitute the entire television instruction. Our present television sequence consists of 56 skits. In each 20-minute instructional segment the skit is shown three times, together with "frames" which provide grammatical explanations, vocabulary explanations and guidance for understanding idiomatic expressions and cultural differences. The series of skits has been carefully graded in difficulty in coordination with the grammatical content of the lessons, and provide lexical and cultural enrichment throughout the remainder of the first-year course. Sample excerpts from both a grammatically simple and a grammatically complex skit follow below.

Skit "Der Detektiv" (Sixth week, 1st quarter):

(...) Sie sind vielleicht Detektiv.

Wie, bitte?

Was ich gesagt habe; sind Sie Detektiv?

Wieso?

Sie beobachten den Mann und die Frau; Sie sind wohl Detektiv. Detektiv? Aber gar nicht. Ich lerne Deutsch. Das klappt, nicht wahr?

Sie lesen eine Zeitung.

Nein, ich lese keine Zeitung. (Schuittelt den Kopf.) Ich stehe auf, ich gehe - (ab.) Ich bin gegangen.

Skit "Die Brücke" (5th week, 2nd quarter):

(...) Ach, du kennst Heinrich. Jedesmal wenn sein Mädchen ihn verlässt will er ins Wasser springen.

Immer von der Brücke?

Immer von der Brücke.

Von dieser Brücke?

Oh nein, es braucht nicht diese Brücke zu sein; - von irgendeiner Brücke. Es macht ihm nichts aus, von welcher Brücke er springt. Es kommt nur darauf an, zu springen. 
Tja. Das ist komisch, dass er springen wird.

Nein. Er wird nicht springen.

Du hast aber gesagt, dass-

Nein. Ich habe gesagt, dass er springen will, dass er springen will, aber er wird nicht springen; er kann nicht springen.

Wieso?

Kö́nntest $d u$ springen? (...)

5. Television quizzes on skits. These quizzes are administered orally in television class meetings and the students give written responses to questions, based on what they have seen and heard. These quizzes, begun in the first quarter, are administered at various periods in the first year. To date, ten television quizzes have been produced. Our final goal is 20 quizzes which will be inserted into the sequence throughout the three quarters.

6. Mini-scenes. These segments are ten to thirty seconds in length. At the present time there are two different kinds-first the so-called "Fussgesprache" which are short verbal interchanges with a punch line, while action is shown through the movement of legs and feet, as illustrated by the following script:

Unterm Tisch, sie hat keine Schuhe an, sie betastet senine Fusse mit ihren.

$\mathrm{Du}-($ Verliebte Stimme)

$\mathrm{Ja}$ ?

Ich mochte dir etwas sagen.

$\mathrm{Ja}$, Liebling?

Deine Fitsse sind kalt.

The second kind of mini-scene presentations, the "Automat" sequences, show two participants engaged in conversation in front of a vending machine with a variety of situational differences.

Since the skits and mini-scenes constitute a television "textbook" (spoken "reader"), a written text is not provided for the students. They are, however, given a list of vocabulary items, which facilitates the understanding of the new material, since the structures used have already previously been internalized. Thus, the student is strongly encouraged to listen and watch very carefully. This process increases his aural comprehension ability and adds a number of visual and oral variations of the patterns and items which he has learned.

7. Student skits. This type of approach to foreign language learning stimulates the students to such an extent that they are motivated to write, either individually or as a team, skits of their own in the second and third quarters. This is done in the nature of a contest. The best two or three studert skits, corrected in collaboration with the 


\section{Contribution of Television}

classroom instructor, are acted out in our television studios and are video-taped and replayed as part of the regular television instruction. We are including below an excerpt from a student skit, which exemplifies the level of language proficiency of our students at the end of the second quarter. We should note that the corrections made by the classroom teacher are minimal and often only concern themselves with grammatical items which had not been introduced to the students prior to the time at which the skits were written:

In einem kleinen deutschen Souvenirgeschaft.

Ein Amerikaner: Diese Kuckucksuhr ist ganz schön, nicht wahr?

Seine Frau: Ja, das stimmt. Sie ist ganz schon.

Der Amerikaner: Pass mal auf! Ich werde sie für den halben Preis bekommen.

Seine Frau: Das wäre grossartig. Aber ich weiss nicht . . . (später, im Laden)

Der Amerikaner: Ich werde Ihnen höchstens fünfundvierzig Mark dafür geben. Das ist mein letztes Angebot.

Der Verkaufer: Ja: abgemacht. Fünfundvierzig Mark. Móchten Sie einen Karton?

Der Amerikaner: Nein, hier ist das Geld.

Der Verkaufer: Und hier ist Ihre Kuckucksuhr.

Der Amerikaner: Auf Wiedersehen.

Der Verkaufer: Auf Wiedersehen.

(Der Amerikaner und seine Frau gehen aus dem Souvenirgeschaft.)

Der Amerikaner: Ich habe gesagt, dass ich sie fur den halben Preis bekommen könnte!

Seine Frau: Ja, du bist wunderbar.

(Der Amerikaner sieht die Rückseite der Kuckucksuhr an. Er sieht etwas ...)

Der Amerikaner: "Made in Japan."

It should be noted further that not only the students who write the skits are involved in these productions; those who do not wish to write scenes assist in technical matters, in acting out the skits and in other capacities, so that there is a total individual and group immer. sion in the production effort.

\section{B. Assessment}

It is understandable that a course incorporating the above components is a very popular one, and indeed our surveys of student opinion have indicated this. Nevertheless, in our efforts to prefect the program we have noted several items which we will concentrate upon in the future in order to improve the sequence. In this regard, feedback from the students has been particularly helpful. We have ob- 
served that our current television sequence does not always take full advantage of the potential of the medium. Camera work could become more functional to serve the purposes of the skits, and the visual appeal of some grammar units could be improved by varying camera angles, for instance. Due to technical limitations it was at times necessary to shoot entire 20-minute segments with one camera in a stationary position and no technician in attendance. Furthermore, a variety of trick shots and superimpositions, as well as more visual aids, such as charts, slides, filmstrips, and others could be incorporated in order to make a visually more effective presentation. A revision of some scripts would also improve their quality and timeliness.

Production and course schedules were sometimes the overriding considerations and a slight sacrifice of quality had to be the consequence of it. The projected retakes are a normal part of our efforts to continually improve the sequence. Even at this stage of development, the technical and pedagogical levels which we have achieved, in our opinion, have brought us close to the final goal. This level was reached after several revisions which constitute a time-consuming process from the idea to its implementation and realization on the television screen. The advantages and the potential of the medium were gradually recognized and taken advantage of as the work progressed over the years.

\section{Aspects Of Production Of Instructional Television Presentations}

The current sequence of instructional television programs, constituting approximately 2,500 minutes of air time for the first-year, course, were produced at the University of Minnesota, Department of Media Resources studios, which provided its personnel, including directors, crews, and technical equipment, as well as materials for video-taping, storage and closed-circuit telecasting. The idea for the sequence as well as the original draft of all scripts orginated with Cecil Wood; the current version is the result of a team effort in which both colleagues and graduate students of the Department of German at the University of Minnesota participated. The acting in the skits was done by interested teaching assistants and faculty members of the Department of German. Except for one instance in which a small grant was used to produce some of the skits, no financial compensation was involved; thus the departmental budget was not utilized for production purposes. Without the enthusiasm and the cooperation of these participants, the production of this television series would not have been possible. 


\section{Contribution of Television}

On the whole, we achieved maximum results with a minimum of expense involved. For example, a plane in motion was similated in the studio by using a slide of a plane and then utilizing camera techniques, namely dollying out, to give the visual impression of a plane take-off. In another scene, a slide of the interior of a plane was incorporated by means of rear projection; actors sitting in front of it in chairs, which imitated airplane seats, appeared to be actually sitting in a plane. Furthermore, slides of exterior and location shots were utilized to give the illusion of live location shooting. It is not our purpose to go into the production aspects in great detail, but rather to present a brief description and appraisal of the production process.

Writing each unit for the television instructional sequence, even a relatively simple grammatical unit, is a time-consuming process involving the following steps:

1. Before the script is written, the 20 -minute unit has to be subdivided into 5-minute segments, since it was found that a 5-minute time period is the maximum time span for which the attention of the student can be focused on one problem. This time span is taken into account in planning the rest of the procedure in the production of the unit.

2. The grammar explanations are then rewritten as concisely and simply as possible.

3. Next, sample sentences which best illustrate the grammatical point studied are selected from the textbook. Sample drills are chosen to engage the students actively. This active participation is considered a crucial factor in the success of our television sequence; it should be noted that it is elicited in large television classroom meetings through the medium of television alone. At the end of each instructional unit, a brief summary of the grammar which has been covered is included, as well as an assignment which acts as a bridge between the current lesson and the lesson to follow. Writing a grammar unit of 20 minutes length takes approximately one hour. Memorization of the script by the television teacher, consultation and preparatory work with the television producer, taping of the segment, as well as editing take approximately three to five hours, bringing the total amount of time needed for producing each segment to approximately six hours.

In the writing of the skits, a basic situation or idea is built around a specific concept in the grammatical sequence, incorporating idioms and structures to be taught through the skit, all of which lead up to a final punch line. The script is then written around the outlined framework, with sequences which apply the particular grammatical rules. For instance, in a skit called "Die Brucke," (excerpted above), 
which is shown in the first half of the second quarter, the entire situation is built around the likelihood that a man may jump from a bridge because his girlfriend has left him. This situation gives occasion for the use of a variety of tense forms and tense modalities such as: er mochte springen, er springt nicht, er will springen, er wird springen, er wird nicht springen, als ob er springen wurde, concluding with the punchline after the act has occurred, er ist gesprungen. Writing - the script for such a skit of two or three minutes takes an average of - one and a half hours once the idea exists. The typing, mimeographing, extracting of vocabulary for the students, casting, rehearsing, studio taping time, etc. amount to above hours, of which three are spent in the studio. This amount of time can be considered the absolute minimum. The frames which accompany each skit include explanations of grammar, idioms, cultural differences and special phases which occur in the skit; these consist of two 5 to 7 minute parts. About two hours are needed for the writing and producing of these frames, including the time spent in the studio. The television quizzes require a total of one and a half hours of writing and studio time, while the mini-scenes demand between one and two hours of writing and pro. duction time.

While the current series of television programs has been taped in black and white, the addition of color studios at the University of Minnesota as well as cur wish to perfect the current sequence, both technically and artistically, cause us to anticipate an increased amount of studio time in the future. We do, however, feel that the enormous amount of time and effort invested in the production of this instructional sequence is justified, since the television skits seem to be very effective and stimulating and to increase aural comprehension in learning German. Furthermore, they reinforce the connection between environmental situations and language items learned. Because of the tremendous amount of time involved in the production of such television programs, it would be needless duplication of effort if every institution and school would produce its own television instructional sequence. Taped programs such as ours, which have been produced under carefully controlled studio conditions and which exist on highquality master tapes, and of which $1 / 2$-inch and 3/4-inch duplicates are available, can be distributed and/or exchanged with other institutions, particularly since the skits and mini-scenes are coordinated to partial grammatical knowledge but not specifically tied to our grammar program. Thus they can be used as a supplement in teaching first-year German regardless of the basic textbook or the grammar approach used in any instructional setting. 


\section{Contribution of Television}

Television In Language Programs: Its Utilization, Effects And Interaction With Other Components

Our current television instructional sequence utilizes several characteristics of the television medium in order to improve the learning situation:

The skits constitute slices from real life in replicated form, and therefore allow us to present things to large numbers of students which could not be presented in any other way and could not be reproduced in the classroom. We utilize television for those parts of the instructional sequence which can be done more effectively through that medium. The material can be presented in a more controlled fashion and the organization of our television segments is optiomally structured according to our experience, and can be repeated in that form. The quality of each television lesson is continually improved through retakes of segments or entire units as desired or necessary. Technical procedures such as editing or montage techniques for shrinking and collapsing of time segments allow us to make a more efficient presentation. The utilization of various camera angles and types of shots for certain purposes causes the student to associate certain kinds of performance with certain visual material. Thus, each time a tight shot of the television instructor is shown, the student knows that drilling will begin. Television by its nature enables the instructor to address each student directly and equally intensely via the screen, even though they are all sitting in a large classroom. The television medium makes available a good teacher to a larger audience. In our particular case, a specialist in the description and analysis of German grammar who is also an experienced teacher is repeatedly available to an unlimited number of students. Thus the effectiveness of a good teacher is multiplied, and his effectiveness is bound by neither time nor place.

Confining explanations of grammar and drilling to television presentation redefines the role of the classroom instructor and frees him for more important tasks. Our experiments have clearly shown that it would be absurd to speak of replacing the classroom instructor, since he is the main stimulus for the application and use of language strings by the students. Currently, all students in this course attend the telecast of the television lesson twice a week in groups of no more than 80 students. The other three hours of instruction each week are spent with the classroom instructor in the student's respective small group.

Each telecast is structured as follows: two 20-minute units are shown with a 5-minute intermission in which mini-scenes are presented. Our experience has shown that a 20-minute segment is the

NALLD Journal 
maximum time over which the student's attention can be held. In the first quarter, each television lesson consists of two grammar units of 20 minutes each, one of which deals with pronunciation in the first few weeks. In the second quarter, one grammar unit and one skit constitute each television lesson; in the third quarter the grammar has been phased out and each television lesson consists of two skits with a concomitant refinement of grammatical points in the explanatory frames. Assignments given via television build a bridge between the television lesson and classroom work with the instructor in small groups. Thus, learning is reinforced and made more personal by referring students with questions on vocabulary, or phrases and their use, as well as other problems to their classroom instructor. The students are told not to expect their classroom instructor to drill them in the small group meetings or to explain grammatical rules. They, therefore, have a clear definition of the function and use of each particular component.

In these small-group meetings in the classroom, we are concerned with utilization of grammatical structures taught by television and their reinforcement in conversation. We have already alluded to the importance of the classroom instructor. He ties together all parts of the course and utilizes all components for real interaction in the language. As a by-product of the small-group sessions, informal coffee hours and extra, voluntarily attended meetings on an informal basis have become very popular, particularly for practicing speaking. As a result of this year's experiences, both the television lessons and the small-group sessions seemingly are informal and unstructured, whereas this actually is a purposely informalized yet structured approach to the teaching of the new culture and language. The small-group instructor also proctors television classroom presentations and thus reinforces the interrelationship of the class and the television lesson. He makes the television presentation more real since students can ask him questions on the television lesson right there.

Two additional aids are used as components in our oral emphasis German program. (1) Audio tapes closely integrated with the basic textbook, are used for three different purposes: to teach pronunciation, to reinforce and provide a method of checking the answers to drill items, and in the form of "listening tapes," to increase the students" comprehension of spoken German. The student is not given a printed text, but a list of vocabulary items as well as questions which he is asked to answer. (2) The computer is used as a tutorial aid in learning grammar; the student electing this option covers the entire year's grammatical material utilizing this instructional tool.

The response of the instructors teaching this course has been very positive, particularly in regard to the structured informality and the 


\section{Contribution of Television}

lack of grammatical explanations in the classroom. The most frequently made statement regarding this course is that it teaches the student language skills more effectively than any other method that has heretofore been utilized. It should also be stated that this "structured informality" requires, although it does not appear that way, a greater amount of preparation than any other instructional method. The instructor must have a complete command of the appropriate structures for any stage in the program. He also must have at his disposal an adequate number of alternate ways of utilizing the absorbed structures and vocabulary for meaningful interaction with the students.

\section{Look To The Future And Conclusion}

Having found television to be a necessary and highly useful component in teaching first-year German, we are now looking forward to making further improvements in the instructional sequence. We will make the program even more complete by producing more skits to reach our goal of 60 skits in all. We will incorporate more television quizzes, as well as color programs. Moreover, we anticipate the addition of new segments to the program, such as mini-capsules of cultural materials and the new sub-program called "Um zu lernen" which will consist of 10 to 30-second vignettes stressing basic phrases and lexical subsystems ${ }^{8}$ particularly in the first quarter. We also intend to introduce even more variety into our program by using short segments utilizing puppets and other visual material. In spite of the complexity of the current version or projected future versions, the program will be considered subject to further improvement at all times. New developments in the field of foreign language education, such as the current trend toward individualized instruction, have to be taken into account, as well as changes in the language and culture. Since the interaction of students, instructors and course designers is a vital and crucial one, we consider it important that the improvement of courses such as ours has been due to team efforts and will continue to be so.

${ }^{8}$ Gerhard Clausing and Cecil Wood, German Word Finder: A Handbook of Lexical Subsystems for Students and Teachers, forthcoming. 